\title{
Symmetric Combination With Leviathan Combinatorial Theory Applied To Public Choice
}

José Villacís, (E-mail: villacis.fhm@ ceu.es), San Pablo University, Spain

\begin{abstract}
Utility or welfare depend on the number of goods consumed, the variety of such goods and particularly in what order they are consumed from a temporal perspective, i.e. how they are combined. This is our starting point, which is new to economic science. We apply the combinatorial theory to the theory of consumption. Depending on the number of combinations we will obtain different levels of utility. Leviathan is present in our market offering a set of goods, as well as the citizens who seek a beneficial combination. The citizens have to negotiate with Leviathan. But before that they must reach an agreement among themselves. Leviathan knows his combination but the citizens don't. This results in an asymmetric information situation.
\end{abstract}

\section{INTRODUCTION}

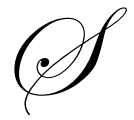

ince Microeconomics was created it has been stated that utility depends on the number of goods that are consumed and the variety of such goods. The theory of utility has tried to be superseded by theories like the indifference curves, the revealed preference, etc. We understand that the theory of utility is still valid as is the idea of welfare. It is not our intention to measure utility or welfare, but to put the accent on this unquestionable and new fact in economic science that is the combination of goods.

There will be as many utilities as possible combinations of goods subject to consumption. Strange as it may be, this idea represents an original approach in Microeconomics.

And it gave birth to several articles that I published in the journal Esic Market at the beginning of the 90's. The main article was published under the title "Combinatorial Theory Applied to the Theory of Utility". These articles meant the integration of combinatorial mathematics into the theory of consumption (there were other articles on combinatorial and production) and led to the creation of other works about combinatorial theory. Such complex field enables the exploration of new scientific continents such as: public funds, asymmetric information in relation to market behavior, the theory of chaos, the theory of bribery, etc.

In this paper we develop the combinatorial theory in relation to public funds where Leviathan is a party and the citizens the other party. Leviathan offers a set of goods that we call universal menu, and a possible combination of those goods. Each party, Leviathan and the citizens, knows the combinations providing them with the highest level of utility, but they cannot obtain such combinations immediately because their interests can be very different. They will necessarily have to negotiate and all of them reach a deal: Leviathan, the citizens individually and the citizens as a group. Such deal means to give up some of their optimum combinations. In other words, they will have to buy other combinations and get, from Leviathan and other citizens, a combination that is not their optimum combination, or the best one, but it is the second best. The art of combining goods and making menus, and the art of negotiating are the core themes of this article.

Leviathan offers goods and services of a nature and in an amount that he and the citizens know. His behavior can be explained through the following two assumptions: one is that his combinatorial action or his menu creating action does not make a difference. The menu is created by the citizens. The other assumption is that Leviathan uses the strength inherent to him to create a menu and impose it. In both cases the negotiation among all the parties, Leviathan with the citizens and the citizens among themselves, will seek to obtain a net improvement in terms of utility. 


\section{THE UNIVERSAL MENU}

We call universal тепи to the set of goods, in terms of quantity and diversity, available for consumption that an individual can consume. At a restaurant the universal menu would be the menu offered to the guest to read. We are not interested in the prices or the income, but the amount and the diversity in particular, the differences between the goods, because it is the diversity that gives the idea of combination its meaning.

Let's take three goods: $(a, b, c)$ equivalent to hamburger, ice cream and movie. These three goods represent the universal тепи. The individual will seek the combination that provides him with the highest possible level of utility. He may prefer going to a fast food restaurant to eat some ice cream and a hamburger and then go to the movies. What is clear for him -and we understand it is logically so- is that he will have to perform two rational operations that most times are intuitive. He will have to make certain combinations, notably all possible combinations, with the three goods included in his universal menu.

The individual will perform three operations: firstly, and a very important one, to combine the goods; secondly, to determine the utility associated with each combination; and thirdly, to establish a ranking arranging the combinations from the most to the least utility providing one.

\section{COMBINATORIAL MATH}

Combinatorial math helps us to combine the elements that take part in the combinations of goods, and particularly to calculate the number of possible combinations.

If we have three goods, they can be combined as follows: (a, b, c), (a, c, b), (b, a, c), (b, c, a), (c, a, b), (c, b, a). A total of six different ways to combine them, each combination providing a certain utility. If we had four goods, the number of possible combination would increase significantly.

Before we go on, we must explain that the term combination corresponds in Math to the part of this science that studies the ordering of elements from a temporal perspective. It is a comprising term that covers partial studies such as: ordinary variations (non-repetitive), repetitive variations, ordinary permutations (non-repetitive), repetitive permutations and combinations strictly speaking. In our example of a three-good combination $(a, b, c)$ we are referring to ordinary non-repetitive permutations including all three goods arranged in different orders. We use the term combination because it is an easy handy word that suggests an instinctive image.

And since we work with ordinary permutations, we will provide a simple explanation. Given a set A of $n$ elements, each ordering including every single element present in A is called ordinary permutation of order $\mathrm{n}$. Therefore, in the above example and in every example enunciated hereinafter (which we will call combination) we are referring to ordinary permutations only. Set A is the universal menu and order $\mathrm{n}$ is the number of goods included in the set -three in our example.

The formula to calculate the number of possible combinations where all the goods are included with not one single good being repeated is:

$\mathrm{P}_{\mathrm{n}}=\mathrm{n}$ !

$3 !=3.2 \cdot 1=6$

Undoubtedly, the combinatorial theory applied to consumption would be enhanced if we incorporated ordinary variations (non-repetitive), repetitive variations, repetitive permutations and combinations to the analysis, but we cannot contemplate them for the moment.

\section{MENUS, RANKING AND OPTIMUM MENU}

Consuming individuals must be free to choose. Such choice means that they are not subject neither to the dictatorship of routine caused by everyday events nor to the dictatorship of cultural or social criteria. The guest should be free to start his meal with dessert and finish with the salad. A citizen should be able to ask, if he wishes so, for an offer of public goods starting with festivals and ending with healthcare services and drinking water. 
Once the guests, or the citizens in our case, are familiar with the menu, then they know the universal menu. This information only is enough to let them calculate the number of possible combinations (ordinary permutations) and classify them.

Each grouping or combination of goods represents a specific menu. Therefore the number of specific menus will be determined by the number of possible groupings, which is $n$ ! If we ascribe an arbitrary value of 1 to the creation of each grouping or specific menu, then the total effort would be determined by $n$ ! efforts. The number of possible utilities would also be measured as n!, which does not mean that it represents the intensity level of each utility.

The next step is to associate each combination to a certain utility -which we are not interested in measuring let alone adding them (it would be ridiculous). Yet we do have an interest in comparing them. In other words, the guests or the citizens distribute the combinatorial packages (notice that we are not saying the goods) in a list ordered from the highest to the lowest level of satisfaction. Such list of combinatorial packages ordered according to the utility they provide is called ranking. This means that the individual has previously compared his utilities and has preferred certain utilities against others.

Finally, the individual will chose the menu providing him with the highest level of utility. That menu is called optimum menu or best menu. The rest are called under-optimum menus and the second is the second best menu. If there is an optimum menu, the number of under-optimum menus will be $n !-1$.

The best menu is a menu that has strongly tied (linked) combinations; the rest have weakly tied combinations and are arranged in a decreasing order. Such weak ties or preferences mean that those menus are easy to negotiate or give up or sell. On the contrary, the best menu (or the second best) is untransferable and cannot be given up.

We must clarify that we do not contemplate the existence of two or more equi-utility specific menus, let alone the existence of two optimum menus providing the exact same utility.

\section{IS FREEDOM FREE?}

The individuals have to carry out several objective and subjective long complex tasks such as the creation of specific menus and a ranking list. We have already seen that if we ascribe an arbitrary value of 1 to each specific menu, then at least the total effort would be determined by $\mathrm{n}$ ! And we say at least because the task consisting in organizing the ranking is still pending, and it represents another effort. When assessing this task, which we suppose does not give any satisfaction, we wonder if it is advisable to be free. We particularly wonder whether it is better to be imposed a certain combination and save ourselves the effort of making specific menus or doing a ranking list.

To answer this question we will use the following example based on chance games. Let's suppose that we write down each specific menu in a piece of paper and that all the pieces of paper (all the menus) are put in a box. The ranking is written in a different piece of paper. We know that the optimum menu is inside the box. We draw a piece of paper at random. At this point we want to know what is the probability that the piece of paper drawn corresponds to the optimum menu.

The probability will be:

$1 / \mathrm{n}$ !

It is a very small value. In fact, the larger the number of goods included in the universal menu is, the smaller the value becomes. In view of this risk, it is natural that the individuals -the guests or the citizens- prefer to create the specific menus and the ranking and make a choice rather than losing the best menu.

\section{THE THEORY OF THE SLAVE}

We must however consider the possibility of a fight or conflict with other citizens or with Leviathan requiring an effort such that it casts doubt on that freedom. Some may think that in addition to the efforts already mentioned making specific menus, doing a ranking list and choosing- they will also have to make the effort of fighting with other forces in order to obtain one's own menu. These are the cases where a single demander alone clashes with other demanders or with a monopolistic company or, as is the case in this paper, with Leviathan. 
This consumer assesses the maximum utilities provided by the optimum menu, and also understands that these are not net but gross utilities. We mean to say that he deducts the efforts measured as disutilities that arise from the efforts he would have to make to obtain either his own menu or a common best menu for all.

If the consumer ascribes a higher value to the efforts required by disutilities than to the total or gross benefits, he becomes discouraged and lets others chose his optimum menu for him.

This is the case of the slave consumer who lets others create his menu. Leviathan

The citizens or the sovereign people will always avoid the position of the slave menu in their fight against

\section{LEVIATHAN}

Based on Hobbes' theory about the State, Leviathan is an impersonal monster governing the State machine and of course the politicians. He is essentially an impersonal force. He consists of economic and social forces, bureaucrats, technocrats, intelligence services, etc.; the sum of all those vectors represents the utmost force vector, which corresponds to Leviathan.

Our creature offers a universal menu consisting of goods and services (hereinafter globally referred to as goods) for the citizens to consume. Depending on whether Leviathan's position is perceived as neutral or belligerent, we will be able to say that such menu is simply a universal menu or that it is already determined as a specific menu being offered.

\section{Indifferent Leviathan}

We consider as strong a Leviathan as we can possibly imagine, but also a Leviathan that is the result of opposite force vectors, and therefore we cannot say that he has a personality, let alone a resolute mind. He has no plans or defined orientation because those forces are in opposition, and this leads to a neutral or indifferent behavior toward the outside. Leviathan offers a universal menu for he believes that such is his obligation, yet he has no intention of making a specific menu or imposing an optimum menu.

In these circumstances, citizens do not have to fight against Leviathan in order to avoid being imposed an optimum menu that will not necessarily correspond to each citizen's optimum menu. However, they will fight to create a menu that is the closest possible to their optimum menu, even if they do not match exactly. To obtain such menu they will try to create alliances through combinatorial agreements.

\section{Belligerent Leviathan}

In this case the executive power or the State machine is seized by forces consistently united that shape Leviathan's personality and will. Therefore, the creature is consistent in his actions, and wishes and imposes an orientation for his public activity. One of those orientations consists in offering a universal menu, creating specific menus and choosing (his choice) an optimum menu. Such menu will be Leviathan's optimum menu, which is not the optimum menu of each and all of the citizens. Due to the power and selfishness of organized groups, Leviathan will impose his optimum menu.

Citizens will try to avoid such imposition and make a menu favorable to their interests. They are faced with a twofold task: on the one hand, they will have to make a combinatorial deal among themselves aimed at defining a menu favorable to their interests; and on the other hand, which is the most difficult, they will have to negotiate with a belligerent Leviathan so that he abandons his intentions.

The reality or hypothesis of an indifferent Leviathan or a belligerent Leviathan has nothing to do with the existence of a democracy or a dictatorship. The condition of indifference or belligerence is based on whether the internal or external components that type on the State computer are oriented in the same direction so that they can constitute a single will and a single power. Such is our vision of the State, expressed in our book "The Machine. Beyond Leviathan" (1984). 


\section{THE WELDS}

Given any specific menu, including the universal menu, there will be certain internal combinations that are tightly tied or are intensely preferred. In other words, there will be some goods that are combined in a special way or are intensely preferred compared to other combinations within a specific menu. We call these combinations welds.

There will be $\mathrm{n}^{\prime}$ elements included in the combination, which will obviously be a smaller number than the elements (goods) included in the universal menu $\left(\mathrm{n}^{\prime}<\mathrm{n}\right)$. Let's use the following example: Given a set of 11 goods (a, $\mathrm{b}, \mathrm{c}, \mathrm{d}, \mathrm{e}, \mathrm{f}, \mathrm{g}, \mathrm{h}, \mathrm{i}, \mathrm{j}, \mathrm{k}$ ) that is the universal menu, and given a combination or specific menu (b, c, a, e, d, k, j, h, i, g, f) that corresponds to the optimum or best menu, let's imagine that the most intensely preferred combination within the whole combination is $(j, h, i, g)$. Then this last combination is a weld. Such weld consists of 4 elements, a smaller number that the 11 elements of the universal menu and also the optimum menu $(4<11)$.

Welds originate from the same process of choosing, making menus and establishing a ranking. Given the possibility to make several menus and arrange them in a ranking according to their utility, it is perfectly understandable to choose a special combination within each menu.

The very nature of combinatorial theory shows us that there can be a weld common to more than one specific menu due to the fact that some combinations may be changed, yet a part remains unchanged -that part is the weld. In the above example, the rest: (a, b, c, d, e, f, k) can still be combined to make other specific menus.

The existence of welds is an indication of certain preferences that do not prevent from thinking that there may in theory be another element subject to change.

Also, welds do not rival other combinations in value. They are not opponents.

Welds are important in our work because they are basic elements in negotiations, since they represent those parts of the menu that resist being given up or negotiated.

\section{THE EXISTENCE OF HARD CORES AND RANKINGS}

Given the existence of several welds within any menu, including the best menu, we call hard core to the most highly valued weld.

The consumer should create a special ranking for welds only, and chose the best weld. However, we realize that for these purposes it is possible to create two types of rankings: a horizontal and partial ranking and a vertical and comprehensive ranking.

Horizontal ranking is the creation and assessment of welds within one specific menu. It is a partial ranking because it does not cover every specific menus but just one, any one. A vertical ranking covers every specific menu (up downwards); it separates and assesses all the welds in each menu and arranges all of them (which represent all the welds from the universe of welds) according to a ranking.

The existence of hard cores is based on the most highly preferred or valued weld of all the welds included in the vertical or comprehensive ranking.

Since the universal menu is incorporated into the ranking, which represents the universe of menus, then the hard cores correspond to sub-groupings within each specific menu, as well as sub-groupings of welds. If there are $\mathrm{m}$ welds, there will also be $\mathrm{m}^{\prime}$ hard cores as part of the welds. And we will find the following disparities:

$m^{\prime}<m$

\section{SOFT COMBINATIONS}

Within each menu there will be several combinations that are weakly preferred or less preferred than welds, and much less preferred than hard cores. We call them soft combinations.

The existence of soft combinations within each specific menu cannot be fully guaranteed. Their existence is just a possibility. 
Since these types of combinations are not intensely preferred, in a negotiation they can be exchanged for other combination or combinations. However, we should not infer from this statement that soft combinations are indifferent to the individual; it is just that they are weakly preferred.

If their existence is a possibility, it is difficult to calculate their number and the number of goods included in them. Such assessment can be made with hard cores and welds, but not with soft combinations.

In a negotiation, a guest or a citizen may release from any menu the goods included in his soft combinations, and yet the utility would hardly be affected. Why then free the goods included in such combinations from all obligations with the menu? In order for other individuals in the same situation to release other types of goods enabling all of them to make a new combination favorable to their interests. This entails a difficulty that we will overcome. Such difficulty lies in the fact that the goods released by the individuals do not necessarily match the goods included in everybody's soft combinations. However, it is very likely that there are certain goods (not all) common to everyone.

If it is possible to make a grouping of released common goods, it is also possible to reach a consensus as to which is the one specific combination defining a common utility that improves the welfare situation. This idea or this possibility is an additional argument facilitating a negotiation among the individuals and/or between the citizens and Leviathan.

\section{NEGOTIATING WITH BELLIGERENT LEVIATHAN}

Leviathan, internally united by a common will, shows a universal menu and offers it as a specific menu of interest to him. Such menu would be Leviathan's optimum menu, which is the menu that interests the groups forming Leviathan.

It is a different menu than the menus owned by each citizen. Yet, the issue is complicated because the citizens will experience an additional insecurity.

\section{CITIZENS NEGOTIATING AMONG THEMSELVES}

Agreements in the creation of a common menu among all the citizens do not necessarily involve a better utility and welfare level. We can even affirm that the creation and eventual consumption of a common menu could lead to a loss of utility, since individuals would not be consuming their optimum or best menu.

Why then would they be interested in making a common menu? Because of the possibility of being imposed a menu by Leviathan that is very different both from their own best menu and from a hypothetical common best menu. Such fear will make them get organized and reach a consensus about a common menu.

The first stage of the negotiation involves everyone bringing up on the table the combinatorial packages, i.e. their specific menus. And then it requires that everyone gets to know all the menus and reach an agreement. This agreement will consist of several partial agreements.

Firstly, the individuals will release the goods included in their soft combinations, and those goods (easily released) will be voted to integrate a common combination. This is an important step forward because all the citizens' will becomes bonded by such special combination. That combination, or partial menu, is a part of the common optimum menu. Obviously, it does not represent the full menu.

This new combination will also be a common soft combination from the common optimum menu that the citizens may release or give up in further negotiations with indifferent Leviathan. In other words, citizens will be willing to be bribed by Leviathan in relation to those soft combinations. We will also say that Leviathan will react to the threat posed by the citizens, and this will lead to a negotiation.

The second stage will involve making an inventory of the welds, starting with the least valued. The welds will obviously be different for each citizen, but there will be parts or portions of combinations that may be common to them. For instance, if Leviathan offers 20 goods, a common weld could be (not always, not wholly): (drinking water, hospitals, roads). Other groups will prefer (drinking water, hospitals, electricity), and others (drinking water, hospitals, fireworks). A common weld would be: (drinking water, hospitals). We could add two types of covenant: a covenant regarding the above-mentioned common weld (drinking water, hospitals), and another covenant linked to other welds 
that, although different, could be welded. For instance, (roads, electricity, fireworks). The latter type will not correspond, like the former, exactly to a weld, that is, to a portion of a best menu, but they represent something that is of interest for everyone as a project of a portion of a second best menu.

We cannot find a solution for hard cores, which will most probably be different for each citizen. There is no possible solution. However, the rest of the goods can be voted to make a combination; a vote encouraged by the imminence of the common pact, or to be precise for fear of being imposed an unwanted combination. Yet, we have already said that this combination is not easy due to the fact that hard cores are intensely preferred. The last possibility is a chance game around chance-weighted choices. Citizens would write down their hard cores and place the pieces of paper in a box. In this case, chance would always work in favor of the vote. Furthermore, in case there were pieces of paper with two or more hard cores, chance would always work in favor of a democratic equal vote.

If Leviathan is indifferent to any common optimum menu whatsoever, then considering a negotiation with him is absurd. The citizens will present the menu they are interested in and Leviathan will have no arguments to reject it. However, the situation is different with a belligerent Leviathan who wants to impose his menu for it servers his own interests.

\section{BELLIGERENT LEVIATHAN VS THE CITIZENS.}

Leviathan is made up of individuals who, united by different interests, form a group of people motivated by the fact that the menu corresponds to a certain combination. Such groups create several specific menus and choose their best menu, which we call Leviathan's best menu. This menu goes in and out of the State machine and is tried to be imposed on citizens.

Once the citizens present the project of a common best menu, they will behave as a single citizen. They represent a united consumption unit with a defined map of preferences. Also, as a united group, they become strong, and that strength and power rival Leviathan's. Such common optimum menu will not match each individual best menu, but it will be the closest: first, it is a menu made from the citizens' own preferences; and second, it is not belligerent Leviathan's menu.

Before we move forward in the negotiation, we must point out a supposition or possibility, which is that Leviathan's optimum menu matches or is very similar to the group menu. If such a coincidence occurred, a negotiation would be senseless because the parties would reach an agreement automatically.

If it did not occur, a negotiation should take place. The first step forward in the negotiation is citizens blackmailing the State or threatening to hurt the State interests, an action totally unconnected with the economic activity. The individuals form groups, and those groups, which are part of the State, which is part of Leviathan, are concerned by a possible dismantling of the State. Although they do not magnify the argument of the dismantling of the State, they sense the danger of losing their optimum menu, which is the menu that maximizes their utilities. Then, a dispute of interests takes place explained in Economics through the theory of games. We settle the conflict by means of the combinatorial theory.

Indeed, both parties have an interest at least in the production and offer of goods (Leviathan) and in the consumption of those goods (the citizens). Therefore, they do not want to lose. Now, the specific combination is a different story. The negotiation involves reaching an agreement to make a second best menu that meets their interests as much as possible.

In the negotiation it is important to make a distinction between group behaviors and strategies.

Citizens groups and State groups may confront each other or they may come closer to each other because of their similar interests. This may happen before the final covenant. The groups will tend to move away from their big brothers and spontaneously get together as sub-groups. Such factions entail an attraction or welding force as groups. In our opinion, creating such factions to get away from the negotiation between the two parties (and from the group) is not rational because it introduces the possibility of not even obtaining second best utilities, let alone optimum utilities. These sub-groups of citizens separating from the group will empathetically find sub-groups within the State that are searching factions. For instance, given a set of $\mathrm{n}$ goods, the sub-groups of citizens with the weld (...roads, armaments...) will get along better with those sub-groups within the State that have the weld (...armaments, roads...), and of course with the sub-groups having the weld (...roads, armaments...). Although their welds are not exactly the 
same, they are similar, and thus these sub-groups interconnect their welds in order to keep their utilities. Moreover, there may even be net improvements. Sub-groups coming closer to one another is something that happens spontaneously. It does not correspond to a strategic plan for negotiating. It is like blood vessels that communicate with one another to create tissue in a wound.

As regards the negotiating strategy, we will first deal with soft combinations. Leviathan may release the goods included in his soft combinations just as citizens have. The goods included in Leviathan's soft combinations are not exactly the same as the goods included in the citizens' soft combinations as a group. Yet there will be some goods that are common. Such common goods will originate a combinatorial covenant, and in this context a democratic vote by means of a trial and error method would make sense. Each of the different combinations would be presented and voted. However, the problem here would not be counting the votes -this is simple- but counting the voters. In short, whom are the people voting on each party's side? The quicker answer would be: citizens sub-groups on the one side, and State sub-groups on the other side. Yet this would not be an equal and weighted vote because citizens sub-groups are larger in number than State sub-groups. The problem can be solved not only from a factual pragmatic perspective, but also from the point of view of the very philosophy of democracy whereby sovereignty lies on the people. From our non-political and impersonal approach to the State, citizens act as sovereign individuals in relation to consumption. They impose their requirements on the market, and therefore it will not matter whether they have the leading position when negotiating with soft combinations.

The goods included in the welds and soft combinations originate from the citizen's optimum menu, or common menu. This also applies to the goods in Leviathan's optimum menu. All those goods form a temporary universal hard core, which will be a sub-group of a hypothetical universal best common menu. It is a part of the menu not subject to negotiation because it has already been negotiated and accepted.

The rest of goods are linked by internal preference levels, usually based on each of the hard cores, which are intensely preferred and therefore not subject to negotiation. Within those hard cores there will probably be some goods that are common to welds and soft combinations. Because such common goods have already been set apart to form a universal hard core, each citizen's hard core will contain fewer elements (fewer goods) after a negotiation than before. In the final negotiation there is one more thing yet to do: incorporating individual hard cores and make them fit the universal hard core in order to create the universal best menu.

\section{PROBABILITY IN THE COMBINATORIAL COVENANT}

In the above paragraph a negotiation has taken place resulting in the creation of a common hard core. Yet due to the existence of individual hard cores we have not been able to make a universal best menu. We have also stated that, despite the existence of hard cores, the citizens were willing to negotiate for fear of losing not only their best menu -which is obvious- but also a common optimum menu.

Such fear, equivalent to disutilities - which cannot be measured but can be compared- had moved them to negotiate. The negotiation entails an initial assessment of what is at stake (an eventual loss and an eventual benefit) rationality and a good deal of game or chance, if you wish. The loss is measured according to two probabilities: one is very likely to occur, and that is the loss of their best menu; the other probability is the loss of even their common menu.

The benefit consists in the creation of common welds. In addition, such benefit is strengthened with the elimination of the fear of Leviathan imposing his optimum menu, which does not match the citizens' menu. The probability of losing utilities disappears. Rationality lies in the negotiations carried out, which do not cover all necessary negotiations, for there is still one last negotiation to undertake. This last negotiation should force citizens to give up their hard cores. And this is possible because the chance of being imposed Leviathan's optimum menu would make them accept anything. The possibility that the worst scenario occurs, i.e. a menu that nobody likes, neither individually nor as a group, would make them accept a comprehensive menu.

\section{ASYMMETRY IN NEGOTIATION}

Considering the public market as a whole (Leviathan and the citizens), we introduce the possibility of an asymmetric negotiation. In this type of negotiation one of the two parties knows the optimum combination, and the other does not. This initial idea should not lead us into thinking that one of the parties knows what is best for the other party. In other words, they are all free and wise: individuals in relation to other individuals and to Leviathan, and 
Leviathan in relation to individuals. We will explain this concept of freedom in more depth. A citizen, as a consumer, is not subject to any imposition, not even that coming from the dictatorship of routine or fashion. A consumer may start his meal with dessert, for instance. Obviously, he will not have to submit to Leviathan, not even a philanthropic Leviathan. Both the citizen and Leviathan are free from all types of subjection or social, cultural set of values. If they so wish, they both can prefer a combination starting with fireworks, then music and finally drinking water. This concept of freedom is closely linked to the idea of comprehensive knowledge, to such an extent that they are the same thing. Freedom - which is an intrinsic characteristic of people- is contrary to the idea that people are subjected.

We can consider an imposition by Leviathan within the context of comprehensive knowledge. Since it is him who prepares the budget and offers the products, he has the power to combine them and offer his optimum menu. This hypothesis is a real starting point because it is more likely that Leviathan is more united than citizens, consisting of groups with different interests, ideologies, traditions, sizes. Another argument is the disparity in forces in favor of the State, enabling it to offer its menus. In addition, the State has the means to convince others and therefore the capacity of seducing through political speech. We must not think that the State knows the likings and preferences of the citizens better than the citizens themselves. No one knows better than the citizens what their likings are, and they are also their best judges when it comes to voting.

We cannot reply to this dictatorial solution, but we can examine it from an asymmetric information theory approach. According to this theory, the principal (the sovereign people) asks an individual called agent to carry out an activity (an assignment). Since the agent is the person who better knows both the assignment and him, the result is asymmetric information. It is a type of information that is not distributed like communicating vessels in a perfect competition scenario; on the contrary, it is jumbled. One knows better than the other and therefore the principal must somehow react to counterbalance the moral risk resulting from the asymmetry.

The theory of asymmetric information refers to the disparity existing in relation to the characteristics of a good between the individuals acting in a market. This paper focuses on the combinatorial characteristic, i.e. the optimum menu, rather than on the good itself.

The agent is an active middleman internally and externally consisting of bureaucrats, technocrats and other forces such as economic and social forces that influence the State's will. The agent becomes Leviathan, who is much stronger than any other citizen or group of citizens. He is wiser than the citizens, not as regards the citizens' preferences, but as regards the way to create, combine and offer them. The assignment is public goods and activities.

We advance two arguments here as an answer to the moral risk: The first is private involvement through institutional blackmail to the State. The second is avoiding the referral of the assignment to Leviathan, for this would diminish its power and information. This second solution would require letting private companies offer and sell the citizens those goods and activities formerly assigned to the State. The suppliers and the demanders would negotiate or auction specific menus until an optimum menu was obtained.

The theory of asymmetric information is applied to life insurance companies, health insurance companies, etc. Why not applying this analysis to the State financial activity?

Any understanding among the citizens, or between the citizens and Leviathan involves a flow and feedback of information that dispels uncertainty. The aim is to have a perfect competition market as regards information on combinations.

\section{CONCLUSION}

The theory of utility explains the behavior of rational, hedonistic and intuitive economic individuals. The reason for their behavior can be found in the nature of the goods, or the variety of goods not only as regards amount but particularly combination possibilities. The core subject of this paper that which provides us with the necessary investigative tools is combinatorial analysis. In this paper, mathematical combination refers to ordinary or nonrepetitive permutations, i.e. to all the different and possible combinations that can be created with all the goods available.

All the goods available to an individual, regardless of how they are combined, are called universal menu. The individual undertakes the tasks of combining all of them (ordinary permutation) and making a list. Each combination is called specific menu, and the ordering and assessment of such combinations according to their utilities (which we do 
not try to measure) is called ranking. The first menu in the ranking is the best menu of all, and we call it optimum menu or best menu. Within each menu there will be groupings, or rather sub-groupings that are ascribed a high value; we call them welds. The sub-groupings that are tightly tied (because they are highly valued or intensely preferred) are called hard cores, and those sub-groupings that are weakly tied are called soft combinations. The goods included in soft combinations are the first to be released in order to be sold or exchanged during negotiations.

The core subject of this paper is negotiations with Leviathan, who can act either indifferently or discretionally. If he acts indifferently, then combinatorial agreements would take place only among citizens with the purpose of creating an optimum common menu, which would not match each citizen's optimum menu. In the event of a belligerent Leviathan, there would also be a negotiation with him. As a contribution to this negotiation, a surreptitious blackmail by the citizens against Leviathan would take place. Finally, they would all together create an optimum common menu. Such negotiations would start by securing soft combinations and then portions of the welds. The basic idea is that they are all interested in having a second best common menu rather than not having a menu at all.

But it could happen that someone has some information about a certain characteristic of an element that others do not have. Such characteristic, which is the combination of goods, lies in the hands of an agent who has been commissioned by a principal. Such information disparity constitutes the basis of the theory of asymmetric information that we apply to our combinatorial theory.

Suggestion for Future Research: Combinatorial Theory in Production, Combinatorial Theory in Consumption, and Combinatorial Theory in the Theory of Chaos.

\section{REFERENCES}

1. Armstrong, W. E., A Note on the Theory of Consumer's Behaviors, Oxford Economic Paper, N.S.,2, 1950.

2. Arrow, J.K., A Difficult in the Concept of Social Welfare, Journal of Political Economy, 58, 1950.

3. Arrow, J.K., Social Choice and Individual Values, Wiley, New York, 1951.

4. Baumol, W.J., Community Indifference, en Review of Economic Studies, 14, 1946.

5. Bergson, A., A Reformulation of Certain Aspects of Welfare Economics, Quaterly Journal of Economics,52, 1938.

6. $\quad$ Boulding, K. E., Welfare Economics, en B.F. Haley A Survey of Comtemporary Economics, 52, 1938.

7. Debreau, M., Representation of a Preference Ordering by a Numerical Function, Thrall, Coombs y Davis, 1954.

8. Harsanyi, J.C., Cardinal Utility in Welfare Economics and in the Theory of Risk Taking, Journal of Political Economy. 61, 1953.

9. Kemp, M.C., Arrow's General Posibility Theorem, en Review of Economic Studies, 21, 1954.

10. Little, I.M.D., A Reformulation of Theorie of Consumer's Behavior, en Oxford Economic Paper,N.S.,1, 1959.

11. Majumdar, T., Choice and Revealed Preference, en Econometrica, 24, 1956.

12. Marschk, J., Rational Behavior, Uncertain Prospect and Measurable Utility, en Econometrica 18, 1950.

13. Mishan, E.J., Arrow in the New Welfare Economics: A Restatement, Economic ??Journal, 68, 1958.

14. Olson, M. N., The Logic of Collective Action, Harvard University Press, Cambridge, Mass, 1964.

15. Rawls, J., Outline of a Decisions Procedure for Ethics, Philosophical Review,60, 1960.

16. Samuelson, P.A., Foundation of Economic Analysis, Harvard University Press, Cambridge Mass, 1947.

17. Samuelson, P.A., Comsumption Theory in Terms of Revealed Preference, Economica, N.J. 15, 1948.

18. Sen, A. K., Distribution, Transitivity and Little's Welfare Criteria, Economic Journal, 73, 1963.

19. Sen, A. K., Preference Votes and the Transitivity of Majority Decisions, Review of Economic Studies.

20. Tullock, G., Problems of Majority Voting, Journal of Political Economy, 67, 1959.

21. Vickrey, W., Measuring Marginal Utility by Reactions to Risk, Ecometrica,13, 1945.

22. Villacís, J., La Teoría Combinatoria Aplicada a la Teoría de la Utilidad. Esic Market. 1993.

23. Villacís, J., La Máquina. La Superación de Leviathan. (books) Editorial Dykinson. Madrid. 2004

24. Ward, Majority Voting and Alternative Forms of Publics Enterprise, Margolis, 1965. 